\title{
Biana: a software framework for compiling biological interactions and analyzing networks
}

\author{
Javier Garcia-Garcia, Emre Guney, Ramon Aragues, Joan Planas-Iglesias, Baldo Oliva*
}

\begin{abstract}
Background: The analysis and usage of biological data is hindered by the spread of information across multiple repositories and the difficulties posed by different nomenclature systems and storage formats. In particular, there is an important need for data unification in the study and use of protein-protein interactions. Without good integration strategies, it is difficult to analyze the whole set of available data and its properties.

Results: We introduce BIANA (Biologic Interactions and Network Analysis), a tool for biological information integration and network management. BIANA is a Python framework designed to achieve two major goals: i) the integration of multiple sources of biological information, including biological entities and their relationships, and ii) the management of biological information as a network where entities are nodes and relationships are edges. Moreover, BIANA uses properties of proteins and genes to infer latent biomolecular relationships by transferring edges to entities sharing similar properties. BIANA is also provided as a plugin for Cytoscape, which allows users to visualize and interactively manage the data. A web interface to BIANA providing basic functionalities is also available. The software can be downloaded under GNU GPL license from http://sbi.imim.es/web/BIANA.php.

Conclusions: BIANA's approach to data unification solves many of the nomenclature issues common to systems dealing with biological data. BIANA can easily be extended to handle new specific data repositories and new specific data types. The unification protocol allows BIANA to be a flexible tool suitable for different user requirements: non-expert users can use a suggested unification protocol while expert users can define their own specific unification rules.
\end{abstract}

\section{Background}

Advances over the past years have yielded a vast amount of experimental high-throughput data on relationships between biological entities such as proteins and genes [1-3]. This information is spread across multiple databases, containing different types of the stored data, accession nomenclature and interface (HPRD [4], MINT [5], BioGrid [6], IntAct [7], MIPS [8]). The main difficulty to merge the data provided in these databases is having distinct identifiers for the same biological entity [9]. Therefore a protocol that unifies biological data independently of the identifiers used on each data source is required. A number of works have addressed the standardization of nomenclature and format of biological entities (HGNC [10], HUPO-PSI [11]) while

\footnotetext{
*Correspondence: boliva@imim.es

Structural Bioinformatics Lab. (GRIB). Universitat Pompeu Fabra-IMIM. Barcelona Research Park of Biomedicine (PRBB). 08003-Barcelona, Catalonia, Spain
}

(c) 2010 Garcia-Garcia et al; licensee BioMed Central Ltd. This is an Open Access article distributed under the terms of the Creative Commons Attribution License (http://creativecommons.org/licenses/by/2.0), which permits unrestricted use, distribution, and reproduction in any medium, provided the original work is properly cited. some others have tackled the problems of redundant data produced by cross-references (IPI [12], PIANA[13], BNDB[14], APID [15], UniHI [16], bioDBnet [17], ONDEX [18] and iRefIndex [19]).

Here we present BIANA, a tool for biological database unification and network management that can be used as a standalone application or as a plugin for Cytoscape. BIANA uses a generic method to find entries of a given molecule that are equivalent across different biological data repositories. Moreover, BIANA incorporates and empowers a variety of network analysis methods through NetworkX [20]. In addition to unifying all major biological repositories, BIANA is easily adaptable to newly created data repositories. BIANA is an extension of the Protein Interaction and Network Analysis (PIANA) [13], which was focused on protein-protein interactions. BIANA bridges the network visualization of Cytoscape and the network analysis capabilities of NetworkX and Cytoscape with customizable data unification 
for relationships between genes and their products. BIANA addresses the challenge of unambiguously gathering available data for biological entities of interest and working with networks built with its relationships. BIANA network-analysis capabilities have been compared with other programs under the same set of features as those presented in Cline et al. [21] (see Table 1). BIANA data integration capabilities have also been compared with up-to-date software focused on data integration (see Table 2).

\section{Implementation}

\section{Software architecture}

BIANA is a Python framework composed of four different modules (Figure 1): 1) Database Management (handles communication between BIANA and MySQL database); 2) Parser Management (imports data into BIANA database); 3) Network management (performs networking operations using NetworkX package); and 4) Session Management (to manage biological data sets and their networks). The Cytoscape Plugin is a separate and user friendly interface to BIANA (the plugin communicates with BIANA \& Cytoscape through a socket).

\section{Data model}

BIANA uses a high level abstraction schema (see Figure 2) to handle databases providing biological information (i.e. individual entries and their relationships). Any data source that contains biologic or chemical data parsed by BIANA is defined as an external database. Similarly, BIANA adopts the concept of external entity, corresponding to entries in external databases, and integrates these external entities coming from different external databases. For example, a Uniprot entry (a protein), a GenBank entry (a gene), an IntAct interaction (a protein-protein physical interaction), a KEGG pathway (a metabolic relationship) or a PFAM alignment are all represented as external entities. In order to achieve data uniformity, the participants of a partnership and its relationship are considered external entities, whereas the relation itself is annotated as external entity relation which is a subtype of external entity. External entities are characterized by several attributes, such as database identifiers, sequence, taxonomy, description or function. Each external entity relation is further characterized by some attributes (i.e. detection method or reliability). Alternatively, the participants in external entity relations can have their particular attributes (i.e. role or cardinality). BIANA unifies external data inserted into its database based on a specific protocol. This protocol, called unification protocol, consists of a set of rules (unification protocol atom) that determine how data in various data sources are combined (crossed). Each rule is composed of attributes crossed and the pair of external databases used. Two external entities (each coming from one of these external databases) will be considered "equivalent" provided that they share the same annotation (value) for the specified attribute(s) in the rule. The set of external entities that are decided to be equivalent with respect to a given unification protocol is called user entity (group of biomolecules that are considered

Table 1 Comparison of network analysis platforms.

\begin{tabular}{|c|c|c|c|c|c|c|c|c|c|c|c|c|c|}
\hline Feature & $\mathrm{CY}$ & GM & VA & OS & CD & AR & IN & GG & $\mathrm{PI}$ & PR & $\mathrm{BL}$ & $\mathrm{PA}$ & $\mathrm{BI}$ \\
\hline Free for academic use & $x$ & $x$ & $x$ & $x$ & $x$ & & & & X & $x$ & $x$ & $x$ & $\mathrm{X}$ \\
\hline Free for commercial use & $x$ & $x$ & $x$ & & $x$ & & & & $X$ & $x$ & $x$ & & $X$ \\
\hline Open source & $X$ & $x$ & & & & & & & $X$ & $x$ & $X$ & & $\mathrm{X}$ \\
\hline Curated pathway/network content & & $x$ & & $x$ & & $x$ & $x$ & $x$ & & & & & \\
\hline Standard file format support & $x$ & & $X$ & & $X$ & & & & $X$ & $x$ & & $x$ & $\mathrm{X}$ \\
\hline User-defined networks/pathways & $x$ & $x$ & $x$ & $x$ & $x$ & $X$ & $x$ & $x$ & $X$ & $x$ & $X$ & $x$ & $\mathrm{X}$ \\
\hline Functionality to infer new pathways & $x$ & & $x$ & & & $x$ & & $x$ & $X$ & & & & $\mathrm{X}$ \\
\hline GO/pathway enrichment analysis & $x$ & $x$ & $x$ & & & & $x$ & $x$ & & & & & $\mathrm{X}$ \\
\hline Automated graph layout & $x$ & & $x$ & $x$ & $x$ & $x$ & $x$ & $x$ & & $x$ & $x$ & $x$ & $\mathrm{X}$ \\
\hline Complex criteria for visual properties & & $X$ & & & & $x$ & $x$ & $x$ & & $x$ & $x$ & $x$ & \\
\hline Multiple visual styles & $X$ & & $X$ & $X$ & & $X$ & $x$ & & & $x$ & & & $\mathrm{X}$ \\
\hline Advanced node selection & $x$ & & $X$ & $x$ & & $X$ & $x$ & $X$ & $X$ & $x$ & $X$ & $x$ & $X$ \\
\hline Customizable gene/protein database & & $x$ & $x$ & & & $x$ & & $x$ & $X$ & & & & $\mathrm{X}$ \\
\hline Rich graphical annotation & & $x$ & $x$ & & & & $x$ & $X$ & & & & $x$ & $\mathrm{X}$ \\
\hline Statistical network analysis & $x$ & & $X$ & & & & $x$ & $x$ & $X$ & & $X$ & & $\mathrm{X}$ \\
\hline Extensible functionality: plugins or API & $X$ & & $x$ & & $x$ & $x$ & $x$ & $x$ & $X$ & & & & $X$ \\
\hline Quantitative pathway simulation & & & & & $x$ & $x$ & & & & & & & \\
\hline
\end{tabular}

BIANA has been compared with the same programs and using the same set of features as the ones presented in [21]. Compared software: CY, Cytoscape [55]; GM, GenMAPP [58]; VA, VisANT [59]; OS, Osprey [60]; CD, CellDesigner [61]; AR, Ariadne Genomics Pathway Studio [62]; IN, Ingenuity Pathways Analysis http:// www.ingenuity.com; GG, GeneGO http://www.genego.com; PI, PIANA [13]; PR, ProViz [63]; BL, BioLayout [64]; PA, PATIKA [65]; BI, BIANA. 
Table 2 Comparison of biological information integration softwares.

\begin{tabular}{|c|c|c|c|c|c|c|c|c|c|c|}
\hline & Feature & $\mathrm{BI}$ & $\mathrm{PI}$ & AP & AP2 & $\mathrm{BN}$ & $\mathrm{UH}$ & MI & ON & iRI \\
\hline \multirow[t]{4}{*}{ Data types } & Supports multiple biomolecule types (protein, gene, compound...) & $x$ & & & & $x$ & & $x$ & $x$ & \\
\hline & Supports multiple relation types (interaction, complex, pathway...) & $x$ & & & & $x$ & $x$ & $x$ & $x$ & \\
\hline & Supports multiple data descriptor/identifiers types & $x$ & $x$ & $x$ & $x$ & $x$ & $x$ & & $x$ & $x$ \\
\hline & User extensible to new user defined data types and attributes & $x$ & & & & & & & & \\
\hline \multirow[t]{2}{*}{ Data Unification } & User specific data unification & $x$ & & & & & & & $(1)$ & \\
\hline & Standard user can extend to new data repositories & $x$ & & & & & & & $(1)$ & \\
\hline \multirow[t]{4}{*}{ User Interface } & Standalone Graphical Interface & & & & & $x$ & & & $x$ & \\
\hline & Scripting/Command line & $x$ & $x$ & & & $x$ & & & $x$ & \\
\hline & Provides a webserver & $x$ & & $x$ & & $x$ & $x$ & $x$ & & $x$ \\
\hline & Provides a plugin for Cytoscape & $x$ & & & $x$ & & & $x$ & & $x$ \\
\hline Network analysis & Adds network analysis methods & $x$ & $x$ & & & $x$ & & & $x$ & \\
\hline Availability & Open Source & $x$ & $x$ & & & $x$ & & & $x$ & \\
\hline \multirow[t]{2}{*}{ Installation } & Does not require additional software & & & $x$ & $x$ & & $x$ & $x$ & $x$ & $x$ \\
\hline & Standalone application (runs locally) & $x$ & $x$ & & & $x$ & & & $x$ & \\
\hline
\end{tabular}

BIANA has been compared with other biological databases integration software/webservers. Compared software: PI, PIANA [13]; AP, APID [15]; AP2, APID2NET [66]; BN, BNDB [14]; UH, UniHI [67]; MI, MIMI [68], ON, ONDEX [18], iRI, iRefIndex [19]. (1)According to the original manuscript, "The installation and use of the data integration methods is still command line driven and requires technical expertise to install, configure and use this component of the ONDEX system".

equivalent). User entities inherit all the attributes of their included external entries. Each external entity can belong to a single user entity, unless the database is defined as promiscuous database, where a single external entity can belong to multiple user entities.

\section{BIANA User Interface}

Depending on user background and objectives, BIANA offers three user interfaces: 1) command line interface for most advanced users (usually bioinformaticians), interested in using all BIANA functionalities, network analysis procedures provided by Network $X$ and other Python modules, and interested in automatic processes by using scripts; 2) Cytoscape Plugin interface benefits users interested in the interactivity offered by a graphical interface without lost of functionality. The plugin has one main advantage: it provides a command line terminal to help most advanced users to create scripts that run in BIANA as a command line application or to execute other Python or NetworkX commands; and 3) online interface for non-expert users who prefer using a web-server that provides only basic functionalities of BIANA. This is the easiest access and it does not require installation. The web-server uses a pre-stored database of interactions with a default unification protocol, but prevents benefiting from the user-driven unification capabilities.

\section{Results and Discussion}

BIANA working procedure has two preliminary steps (Figure 3): 1) installing BIANA package and Cytoscape plugin; and 2) populating a BIANA-database store plus creating one or more unification protocols for this database. After these steps, a working session can be started.

\section{BIANA database creation}

After BIANA installation, the next step consists of creating and populating a BIANA database with desired external databases. BIANA offers several parsers for most well known biological databases (Table 3) and includes most common attributes (identifiers as UniprotAccession, UniprotEntry and GeneID, descriptive attributes as description and function among others). BIANA also offers the possibility to add new parsers for other third-party databases or to add user provided data using a generic format, as well as to add new attributes (i.e. new identifier types or new descriptive types). New parsers for other databases or for user provided data can be uploaded to our project website http://sbi.imim.es/web/BIANA.php?page=biana.parsers and be shared with the rest of BIANA users. For example, we provide three different datasets used in our group (see datasets at http://sbi.imim.es/web/BIANA.php: 1) one dataset contains EC codes (as nodes) and the relationships between them defined by the compounds involved in their reactions (as edges), and it includes several new features such as the number of common metabolites and the direction of the reaction (Figure 4A); 2) a second set contains interactions predicted from sequences/structure distant patterns [22] (Figure 4B); and 3) we have also included a set of transcription factors and their regulated genes plus information on their cooperativity [23] (Figure 4C).

Furthermore, we created a BIANA-database for the convenience of users as an initial starting point to start using BIANA (either from command line or from 


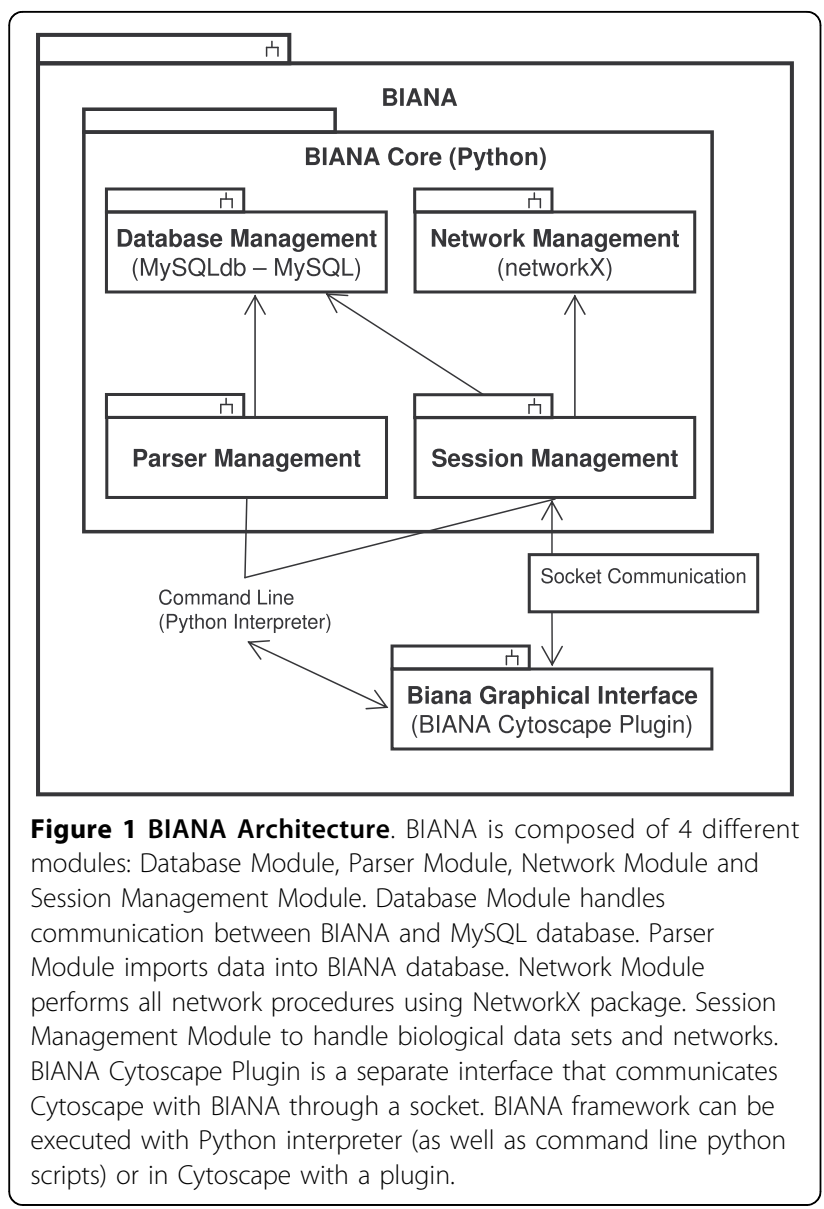

Cytoscape) whose accessibility information is given on the project web page. The online database contains information parsed from the following resources (note that BIANA web-server uses a more complete database whose details can be found on the project page as well): Uniprot Swissprot, Gene Ontology (GO), NCBI Taxonomy database, IntAct database, MINT database, PSI-MI ontology, Reactome, plus specific tutorial sets for the theoretical example and SBI datasets used in previous works $[22,23]$.

\section{Unification protocols}

Once a database has been loaded in BIANA MySQL server, next step consists on the integration of data and its relationships. BIANA utilizes user entries defined by a certain unification protocol chosen by the user. A recommended unification protocol is also provided for non-expert users (Table 4), but users are free to create their own unification protocols according to their needs. As an example, a user may be interested in creating a unification protocol defined by crossing entities using sequence and taxonomy information between two or more databases (similarly to the integration protocol used in PIANA [13] and the Redundant Object Group used in iRefIndex [19]). In another example, the user can use sequence and taxonomy as well as Uniprot accession code between two or more databases. Different unification protocols applied to the same external databases can lead to different outcomes (see Figure 5). The advantages of this unification approach are: 1 ) BIANA database only contains raw data (with exactly the same nomenclature and identifiers of the original data source), therefore it does not entail any assumption on data integration and it allows the user to specify how the integration should be done. 2) Information from a single database or the combination of multiple databases can be selected by the user in each experiment. And 3) the original data can be easily tracked back with all its user interfaces (API, BIANA Cytoscape Plugin and WebServer).

The data available on the online BIANA database is unified with respect to the following criteria of equivalence: All entries coming from any biological data repository are grouped in the same user entity if and only if they share UniprotAccession code "or", both sequence and Taxonomy identifier, "or" GeneID. In particular, when BIANA is queried for ERF1_YEAST as Uniprot Entry code, it groups all the entries coming from Swissprot (P12385), IntAct (EBI-6533), MINT (MINT560710) and Reactome (REACT_1034) in one user entity (a node in BIANA; since they have been annotated with the same Uniprot Accession or sequence and taxonomy or GeneID to that of ERF1_YEAST).

\section{BIANA working-session capabilities}

After creating a BIANA database and creating one or more unification protocols, a BIANA working session includes the following capabilities:

\section{-Network creation}

Integrated biological entities consisting of proteins, genes or drugs are considered as nodes of a network, while relationships between them such as interactions, gene regulation, metabolic reactions or signal transduction are edges. The first step to obtain a network is the acquisition of an initial set of seed nodes (i.e. the biological entities of interest). Then, BIANA creates the network of relationships by retrieving their direct partners (nodes interacting with the seeds). The network construction procedure can run iteratively, defining successive levels of partnership (seed nodes are in level 0 , partners of the seed nodes define the level 1 and nodes connected with nodes in level $i$ define the level $i+1$ ). Users can create the network using various types of relationships and impose restrictions based on the attributes of these relationships or their nodes (for example, by restricting on the detection method). Networks are widely employed to study specific pathologies [24]. 

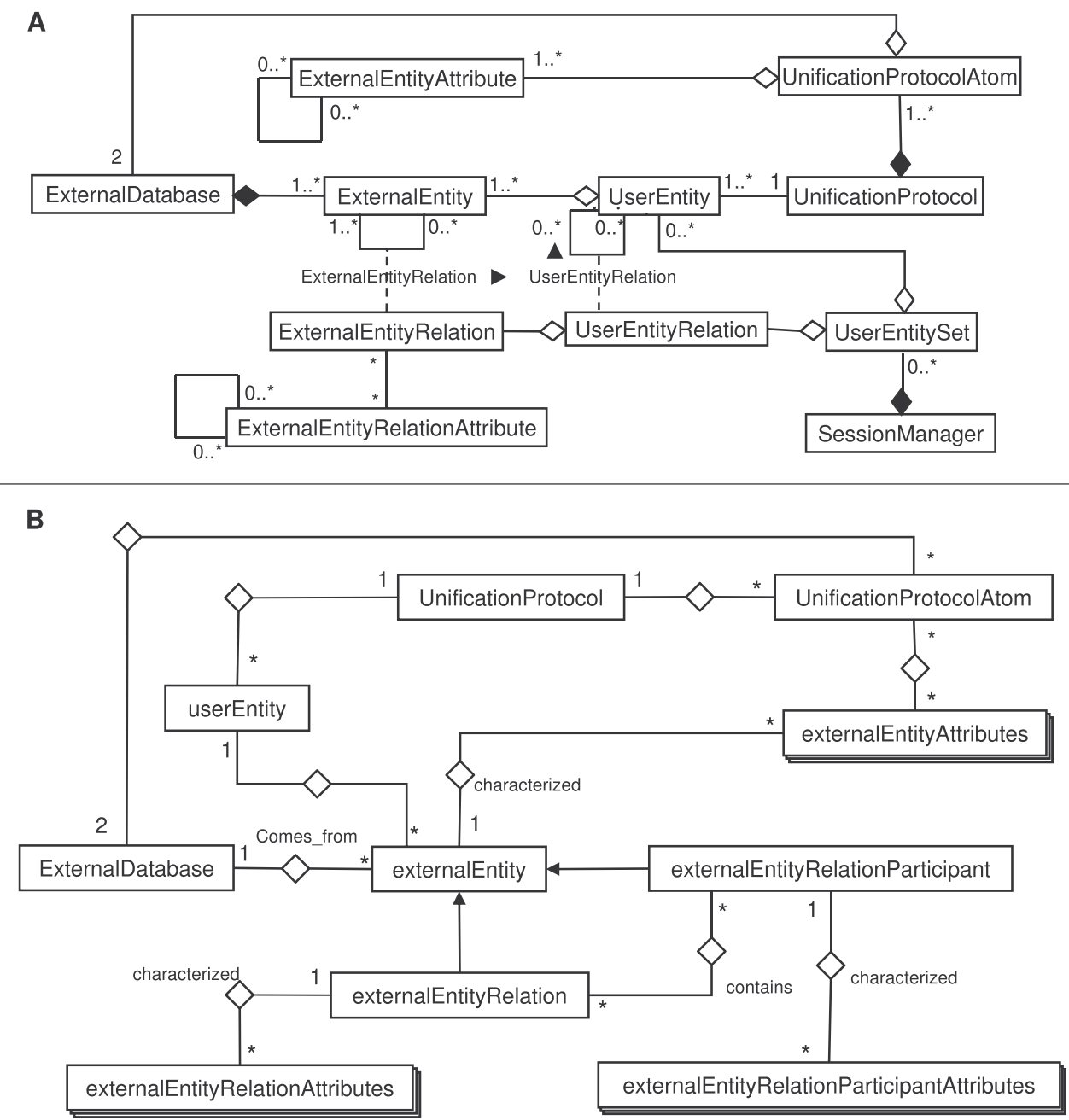

Figure 2 BIANA Data Model. A) BIANA Data Model Diagram. Schematic UML (Unified Modeling Language) representation of the data entries and their relationships in BIANA. Explanation of each element is given in the text. B) BIANA Database Architecture.

\section{-Analysis of networks}

BIANA grants access to most of existing methods for the analysis of networks through Network $X$ and Cytoscape: finding shortest paths and connected components, calculating node degrees and network connectivity, etc. In addition, BIANA includes new methods such as network randomization, node and edge tagging, calculation of linker degree based on node tags [25], intersection and merging of networks. Recently, BIANA has been used in simplifying the improvement of fold recognition using protein-protein interactions [26] or in modeling and analysis of aneurism-related molecular interactions using text-mining seed-nodes [27].

\section{-Predictions of edges}

BIANA predicts novel relationships by transferring existing edges between nodes with common properties. Basically, let $x, y, z$ be biological entities obtained with the unification approach. An interaction is predicted between $x$ and $y$ if: i) $x$ is observed to interact with $z$; and ii) $y$ shares some attributes (decided by the user, i.e. PFAM domains, SCOP domains, or sequence similarity using cut-offs based on e-value or percentage of identity) with node $z$. This is an extension of the definition of interologs [28] using other relationships different than orthology. For example, we generated protein-protein interaction networks from proteins we compared them with networks of protein-protein interaction predictions based on the transfer of interactions between proteins (i.e. y and z) whose $90 \%$ of its sequence could be aligned with at least $90 \%$ of sequence similarity (Table 5).

\section{-Unification backtracking}

As BIANA database architecture and access is pretended to be transparent for users, BIANA offers the possibility of backtrack the results of the unification protocol with the information as defined in original sources. For 


\section{BIANA GENERAL WORKFLOW}
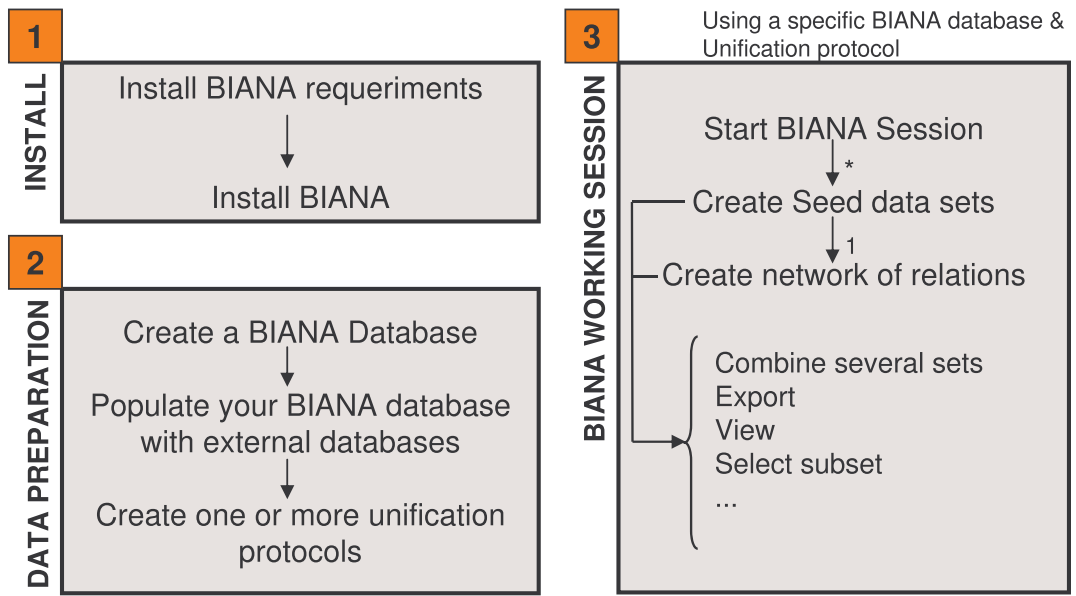

Figure 3 BIANA Workflow. BIANA working procedure involves at least 3 steps: 1) Install BIANA package and Cytoscape plugin if required; 2) Populate BIANA database and create unification protocols; and 3) Start a working session.

example, in the BIANA Cytoscape Plugin, users can check all entries from external databases fused into a single node during the unification protocol. Users can also check which are the exact relationships defined by external databases. These options are explained in the first example of the tutorial. In summary, when selecting the option "View set details" the user can select one or more nodes in the table and click the button "View details". This option shows in a new table all the original entries fused for each node (for example, a BIANA user entity node can contain an entry from the Uniprot
Database, an entry from IPI database, some nodes from a protein-protein interaction database, etc). A similar procedure can be applied to show the relationships as defined in the original sources.

\section{Example: Investigating relationships between pathologies using BIANA}

We have used the study case of the relationship between the networks of genes involved in the pathologies of Alzheimer and diabetes diseases. Under the context of systems and network biology, researchers are interested

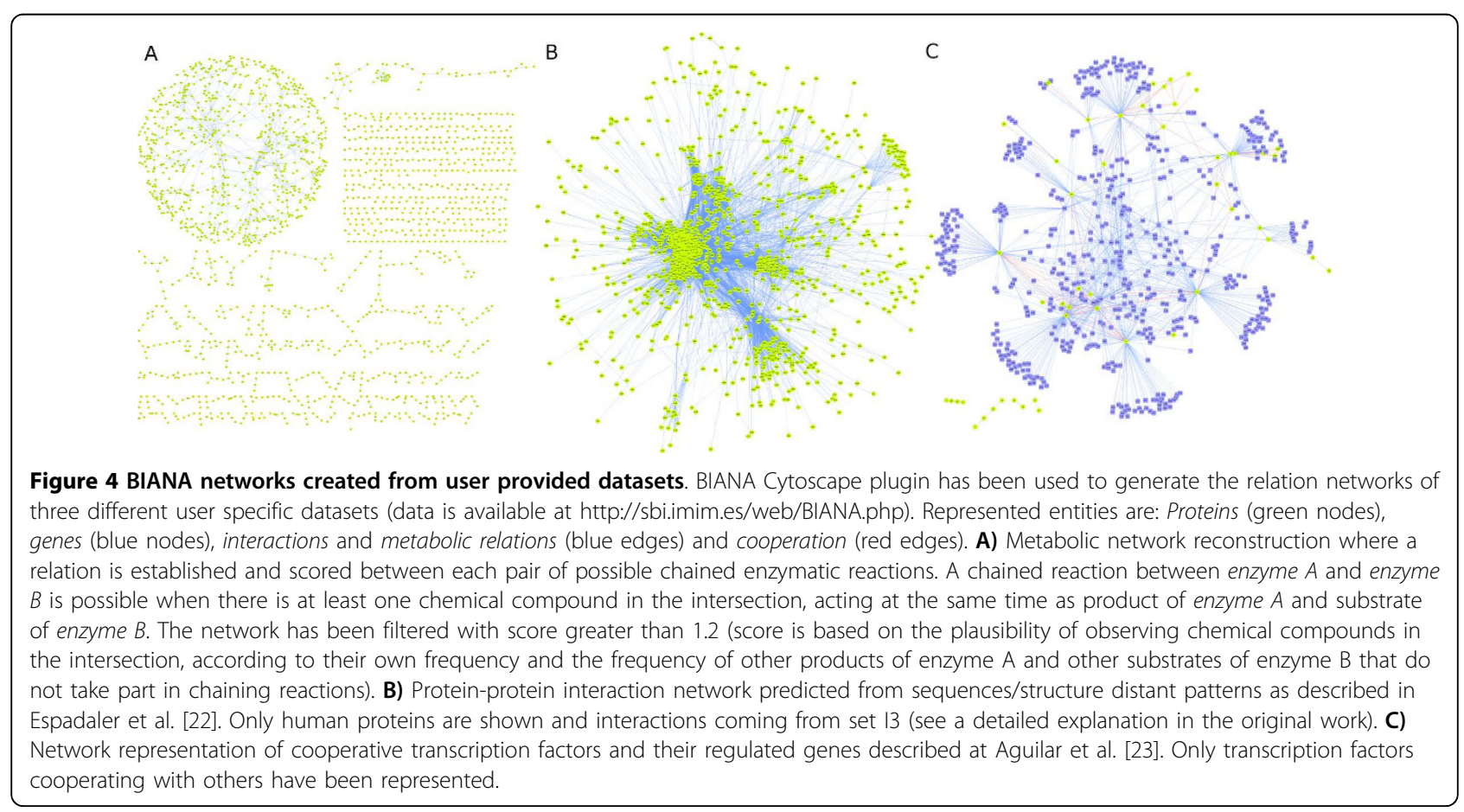


Table 3 Default external database parsers provided by BIANA.

\begin{tabular}{|c|c|}
\hline $\begin{array}{l}\text { External Database } \\
\text { (checked version) }\end{array}$ & Details \\
\hline \multicolumn{2}{|c|}{ General databases (Sequence, identifiers, and cross-reference databases) } \\
\hline Uniprot [31] (Release 14.1) & $\begin{array}{l}\text { Protein sequence, identifiers and functional information (domain composition, description, } \\
\text { function...). Both Swiss-prot (manually curated) and TrEMBL (automatically annotated) can be inserted } \\
\text { into BIANA. Protein sequences and multiple attributes are inserted into BIANA. }\end{array}$ \\
\hline $\begin{array}{l}\text { GenPept from GenBank [69] (FASTA formatted } \\
\text { file) (Release 167) }\end{array}$ & $\begin{array}{l}\text { Protein sequences translated from the GenBank database. GenBank is the NIH genetic sequence } \\
\text { database, a collection of all publicly available DNA. Protein sequences and identifiers are inserted } \\
\text { into BIANA. }\end{array}$ \\
\hline $\begin{array}{l}\text { Non-redundant Blast Database (FASTA } \\
\text { formatted file) (August 2008) }\end{array}$ & $\begin{array}{l}\text { BLAST Non-redundant database from NCBI. Non-redundant protein sequence database with entries } \\
\text { from GenPept, SwissProt, PIR, PDF, PDB and NCBI RefSeq. Protein sequences and identifiers are } \\
\text { inserted into BIANA. }\end{array}$ \\
\hline $\begin{array}{l}\text { International Protein Index (IPI) [12] } \\
\text { (September 2008) }\end{array}$ & $\begin{array}{l}\text { Integrated database for proteomics experiments. Protein sequences and identifiers for Human, } \\
\text { Mouse, Rat, Zebrafish, Arabidosis, Chicken and Cow are inserted into BIANA. }\end{array}$ \\
\hline $\begin{array}{l}\text { HUGO Gene Nomenclature Committee } \\
\text { (HGNC) (September 2008) }\end{array}$ & $\begin{array}{l}\text { Approved unique gene symbols for each human gene. Cross-references are inserted into BIANA. } \\
\text { http://www.genenames.org }\end{array}$ \\
\hline $\begin{array}{l}\text { Cluster of Orthologous Genes (COGs) [70] } \\
\text { (2003) }\end{array}$ & $\begin{array}{l}\text { Collection of orthologous protein sets for prokaryotes and eukaryotes. Protein identifiers and COG } \\
\text { groups are inserted into BIANA. }\end{array}$ \\
\hline \multicolumn{2}{|l|}{ Ontologies } \\
\hline Gene Ontology (GO) [33] (version 1.2) & $\begin{array}{l}\text { The Gene Ontology provides a controlled vocabulary to describe gene and gene product attributes } \\
\text { in any organism. It allows to link in BIANA between GO ID and GO name and type. }\end{array}$ \\
\hline PSI-MI obo & $\begin{array}{l}\text { Controlled vocabulary and ontology for molecular interactions and their detection methods. } \\
\text { Provides the information about and the relation between method ID and method name. http:// } \\
\text { psidev.info/MI }\end{array}$ \\
\hline NCBI Taxonomy [71] & $\begin{array}{l}\text { The NCBI taxonomy database contains the names of all organisms that are represented in the } \\
\text { genetic databases. It allows to link between taxonomy ID identifier to Taxonomy name attribute. }\end{array}$ \\
\hline Structural Classification of Proteins (SCOP) [34] & $\begin{array}{l}\text { Manually curated database with a comprehensive description of the structural and evolutionary } \\
\text { relationships between all proteins whose structure is known. It has a hierarchical classification of the } \\
\text { structural domains. }\end{array}$ \\
\hline \multicolumn{2}{|l|}{ Relation databases } \\
\hline PSI-MI 2.5 Format [11] & $\begin{array}{l}\text { Data exchange format for molecular interactions. The following protein-protein interaction databases } \\
\text { can be inserted into BIANA: IntAct [7] (September 2008), DIP [72] (2008.07.08), HPRD [36] (Release 7), } \\
\text { BioGrid [6] (v2.0.44), MPACT [73] (April 2007), MINT [5] (2008.05.21) }\end{array}$ \\
\hline Biopax Level 2 Format & $\begin{array}{l}\text { Data exchange format for biological pathway data. The following databases can be inserted into } \\
\text { BIANA: Reactome [35] (September 2008) }\end{array}$ \\
\hline iReflndex [19] & A consolidated protein interaction database with provenance. (April 2009) \\
\hline $\begin{array}{l}\text { Kyoto Encyclopedia of Genes and Genomes } \\
\text { (KEGG) [32] }\end{array}$ & $\begin{array}{l}\text { Kegg Ligand (chemical compounds, drugs, glycans and reactions), Kegg genes (genomes, genes and } \\
\text { proteins) and Kegg orthology (ortholog annotation) are inserted into BIANA. }\end{array}$ \\
\hline STRING [74] & $\begin{array}{l}\text { Database of known and predicted protein interactions. Includes direct (physical) and indirect } \\
\text { (functional) associations. }\end{array}$ \\
\hline
\end{tabular}

BIANA provides the following parsers for common public biologic databases. Updated database parsers can be uploaded in the project webpage http://sbi.imim. es/web/BIANA.php.

in discovering actors involved in diseases, their relationships and key shared elements on the organism level. Considering that Alzheimer's disease (AD) and diabetes are shown to be coupled, where having diabetes bears an increased risk for AD [see [29] and [30] for reviews], as an example of the use of BIANA, we look for proteins playing a role both in Alzheimer's disease and diabetes. BIANA is perfectly suited for pursuing such kind of tasks where one needs to fetch species-wide sequence annotation and interaction information spread across various data resources. For this example we integrated data from publicly available proteome knowledge bases such as Uniprot [31], Kegg [32], IPI [12], GO [33], SCOP* [34], HGNC [10] and major interaction data resources such as Reactome ${ }^{*}$ [35], IntAct" [7], HPRD* [36], Biogrid* [6], MINT* [5]. All the databases with a star (*) are inserted as promiscuous. All of the listed databases are unified based on Uniprot Accession identifier; sequence in combination with Taxonomy identifier; and GeneId identifier. In addition to these unification rules, the data coming from SCOP \& Uniprot databases are further unified using PDB codes. For step-by-step details of this case study we suggest to follow the chapter 6 of the tutorial and a video summary.

Using BIANA we identified proteins interacting with an Alzheimer or diabetes associated protein in the mouse proteome (since mouse is one of the most frequently used model organism in studies focused on $\mathrm{AD}$ 


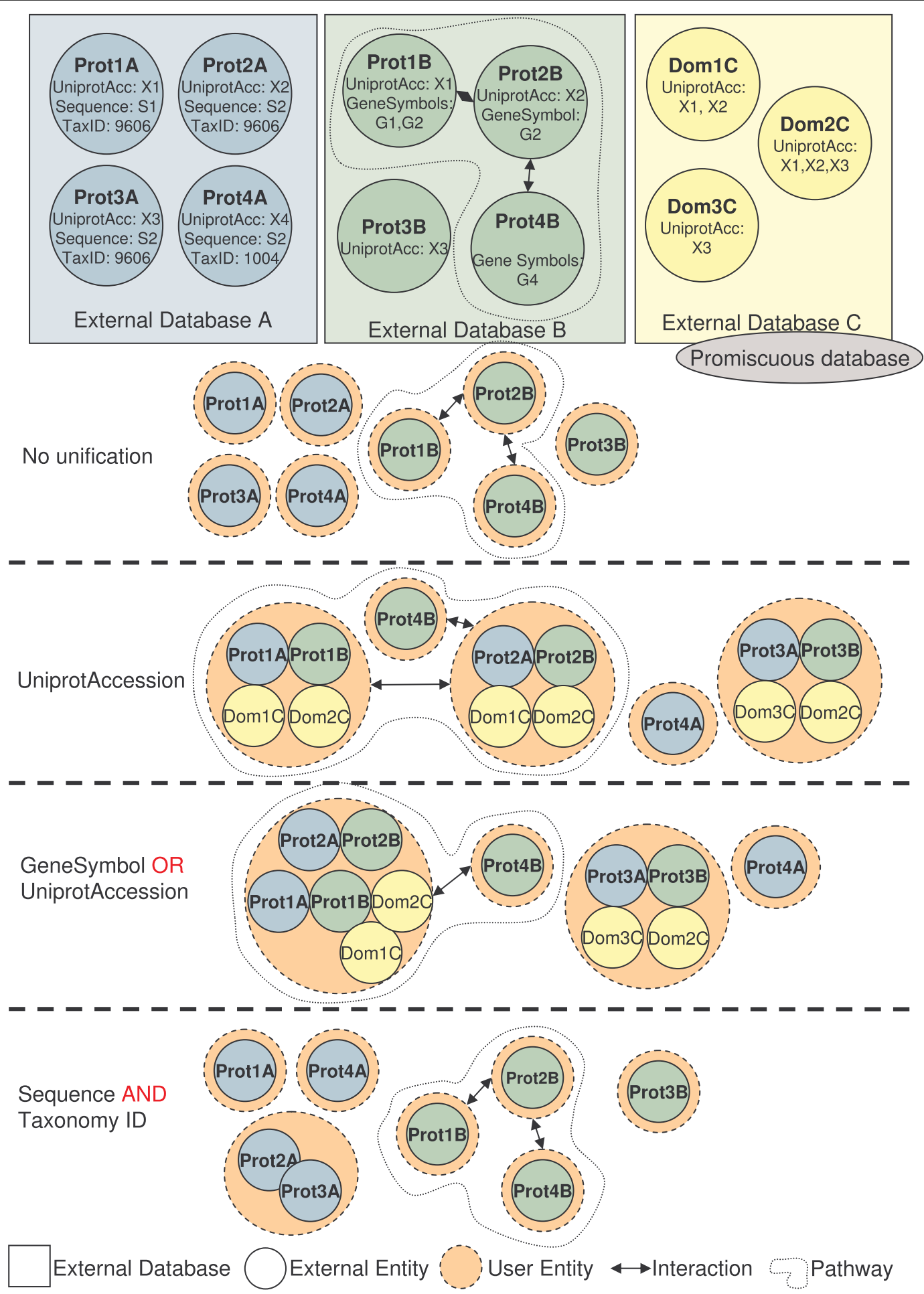

Figure 5 BIANA Unification. Example where three different unification protocols are applied to three external databases (each external database is represented with a different color). BIANA network nodes are individual user entities. Each user entity consists of a set of equivalent external entities. Each external entity can belong to a single user entity, unless the database is defined as promiscuous database, where a single external entity can belong to multiple user entities. External entities in promiscuous databases can not form a user entity by themselves. In this theoretical example, in order to show the importance of the unification protocol, it can be observed Prot1A is merged with Prot $1 B$ when unifying by UniprotAccession identifier, while they are not merged if unification is done by Sequence and taxonomylD. However, when unified by UniprotAccession or geneSymbol, Prot1A, Prot1B, Prot2A and Prot2B are merged. 
Table 4 Recommended unification protocols.

\begin{tabular}{ll}
\hline \multicolumn{1}{c}{ External Databases } & Attributes (identifiers) \\
\hline Uniprot, GeneBank, IPI, KeggGene, COG, String & ProteinSequence AND taxID \\
\hline Uniprot, HGNC, HPRD, DIP, MPACT, Reactome, IPI, BioGrid, MINT, IntAct, String & UniprotAccession \\
\hline Uniprot, String & UniprotEntry \\
\hline Uniprot, HGNC, HPRD, DIP, String & GeneID \\
\hline Uniprot, SCOP(promiscuous) & PDB \\
\hline
\end{tabular}

List of external databases and the attributes (identifiers) proposed to be used in a unification protocol.

and diabetes). Among the proteins contained in the intersection of the protein-protein interaction network, the Mitogen-activated protein kinase (MAPK8; aka JNK1) interacts both with proteins associated with AD and diabetes (in particular, the products of APP and MAPK8IP1 genes, respectively). Strikingly, JNK1 has been demonstrated to be involved in maintenance of neuronal mictrotubules [37], in beta-amyloid-mediated stabilization of p53 [38], and in cell death in the brain of patients with AD [39], but also in major risk factors of diabetes type II such as insulin resistance $[40,41]$ and adiposity [42].

In order to extend our knowledge, we created interaction networks for all proteins stored in BIANA-database that were associated with $\mathrm{AD}$ and diabetes with independence of the proteome specie (thus, being not restricted to mouse). This was possible thanks to the unification protocol used in BIANA. Next, we filtered the proteins contained in these two networks, so that only proteins linked at least to two Alzheimer-associated proteins or to two diabetes-associated proteins were taken into account. Then, we extracted the intersection of these two subsets with BIANA and we selected those proteins that had not been attributed to any of the pathologies in the initial sets. Remarkably, we found direct supporting evidence in the literature that some of the proteins in this selected set were products of genes that had been reported to play key roles in both AD and diabetes (for example, CamKII is related with AD [43-45] and diabetes [46,47]; and GSK3b is related with $\mathrm{AD}[48,49]$ and diabetes $[50,51])$.

Finally, we included predicted interactions (i.e. we transferred interactions from proteins to their homologs pairs). We defined interaction predictions based on the transfer of interactions between proteins with at least $90 \%$ of sequence similarity and $90 \%$ of sequence covered by the alignment. This increased the initial list of potential mediators from 51 to 221 (see more details in tutorial example). A visual inspection on the list yielded some new interesting candidates to be evaluated, such as calreticulin or drebrin. For example, chaperone calreticulin appeared in the literature related with AD [52] and also with insulin receptors [53]. We also found drebrin, which has been related with $\mathrm{AD}$ and diabetes in the literature [54]. Clearly, this example was easily done thanks to the protocols of unification and network handling capabilities of BIANA.

\section{Conclusions}

We have presented BIANA, a software framework designed to integrate several sources of biological data, exploit its relationships and facilitate its analysis. BIANA introduces an abstract data model to allow user-defined biological database unification and an easy to use interface for network creation and analysis. In order to make sure that BIANA would be freely accessible by anybody, BIANA framework uses either free open-source software or publicly available free software. For users who want to skip the software requirements, we provide BIANA web server at the price of loosing freedom on how to decide data unification, relinquishing to incorporate user-defined data and obliging simplified network analysis and visualization protocols.

The main advantage of BIANA against existing software is its design, which allows adding user specific data types and allows the user to handle his own unification

Table 5 Comparison of three different networks at level 1.

\begin{tabular}{llccc}
\hline \multicolumn{1}{c}{ Disease } & \multicolumn{1}{c}{ Keywords } & Initial Set & PPI & PPI + inferred interactions \\
\hline Cancer & Cancer, tumor, metastasis & $985(93)$ & $2782(251)$ & $6272(489)$ \\
\hline Diabetes & Diabetes & $86(10)$ & $284(19)$ & $2121(54)$ \\
\hline Alzheimer & Alzheimer & $30(4)$ & $138(6)$ & $1098(12)$ \\
\hline
\end{tabular}

Comparison of three different networks at level 1 using reported protein-protein interactions vs. using inferred interactions by sequence homology. A BIANA database has been created using the following databases: Uniprot Swissprot, IntAct, MINT, BioGrid, DIP and HPRD. Three different initial data sets related with three different pathologies have been created by a keyword search in fields Disease, Keyword, Description and Function. Two networks at level 1 have been created for each set: 1) using reported protein-protein interactions by third-party databases and 2) using inferred interactions by using sequence similarity (see text for details). For each network we calculated the number of proteins involved in the pathologies according to HEFalMp [75] with a $\mathrm{p}<0.00001$ (shown in parenthesis). By using inferred interactions a higher number of candidates are retrieved. 
protocol. However, unification is a non-trivial problem for non-expert users in bioinformatics. Therefore, we recommend a unification protocol for the databases for which we have provided a parser in our web page. BIANA website also offers a repository where users can download/upload new parsers for other third-party databases and make their own parsers available for the scientific community. Additionally, BIANA helps to handle the network, to expand with predictions or combined resources of information and to extract biologically relevant information from the network (as it was shown in the case study proposed in the example of $\mathrm{AD}$ and diabetes).

We believe BIANA will be of high interest for users who want to incorporate their own data on the analysis with other available biological data sources. It is also noteworthy that other software (or repositories) integrating several sources of interactions can only distribute data if there are no restrictions (or copyright agreements are fulfilled), while in BIANA the user is free to download interactions from official sites and freely integrate them. The capability of executing BIANA as a Cytoscape plugin allows users to benefit from existing Cytoscape plugins in a complementary manner; and the capability of executing BIANA through its Python API allows users to write scripts to access and analyze their data automatically.

\section{Availability and requirements}

- Project name: BIANA. Biologic Interactions and Network Analysis.

- Project home page: http://sbi.imim.es/web/BIANA. php

- Operating systems: UNIX based systems, Windows

- Programming language: Python (BIANA), JAVA (Cytoscape plugin)

- Other requirements: In Windows all requirements are embedded in the software installer. In UNIX based systems it requires g++ compiler, Python 2.5 and MySQL server 2.52. BIANA Cytoscape Plugin requires Cytoscape 2.6.0 [55]. In case one is interested in relations of biological data derived from sequence similarity (such as networks based on interology), CD-HIT [56] and BLAST [57] are also required.

- License: GNU GPL (GNU General Public License)

- Restrictions: Not applied

\footnotetext{
Acknowledgements

Authors thank D. Alarcón, D. Aguilar, J. Bonet and O. Fornés for their helpful comments.

Funding: JGG, EG and JPI are grateful to the support from "Departament d'Educació i Universitats de la Generalitat de Catalunya i del Fons Social Europeu". BO also acknowledges support from BSC and Mare-Nostrum facilities. This work was supported by grants from Spanish Ministry of
}

Science and Innovation (MICINN) BIO2008-0205, PSE-0100000-2007 and PSE0100000-2009, and from EU grant Etox (IMI 115002).

\section{Authors' contributions}

BO conceived of the BIANA project and provided scientific guidance. BIANA software architecture was mainly designed by JGG with contributions of EG. JGG and EG implemented the code for the framework and the plugin and performed analyses. RA implemented the web server whose user interface is later improved by JGG. JP did the analysis on the Reactome network. JGG, EG wrote the manuscript and JP, RA and BO contributed to the final version. All authors read and approved the final manuscript.

Received: 17 August 2009

Accepted: 27 January 2010 Published: 27 January 2010

\section{References}

1. Uetz P, Giot L, Cagney G, Mansfield TA, Judson RS, Knight JR, Lockshon D, Narayan V, Srinivasan M, Pochart P, et al: A comprehensive analysis of protein-protein interactions in Saccharomyces cerevisiae. Nature 2000, 403(6770):623-627.

2. Ito T, Chiba T, Ozawa R, Yoshida M, Hattori M, Sakaki Y: A comprehensive two-hybrid analysis to explore the yeast protein interactome. Proc Natl Acad Sci USA 2001, 98(8):4569-4574.

3. Tong $A H$, Lesage $G$, Bader GD, Ding $H$, Xu H, Xin X, Young J, Berriz GF, Brost RL, Chang $M$, et al: Global mapping of the yeast genetic interaction network. Science 2004, 303(5659):808-813.

4. Peri S, Navarro JD, Kristiansen TZ, Amanchy R, Surendranath $V$, Muthusamy B, Gandhi TK, Chandrika KN, Deshpande N, Suresh S, et al: Human protein reference database as a discovery resource for proteomics. Nucleic Acids Res 2004, 32 Database: D497-501.

5. Chatr-aryamontri A, Ceol A, Palazzi LM, Nardelli G, Schneider MV, Castagnoli L, Cesareni G: MINT: the Molecular INTeraction database. Nucleic Acids Res 2007, 35 Database: D572-574.

6. Stark C, Breitkreutz BJ, Reguly T, Boucher L, Breitkreutz A, Tyers M: BioGRID: a general repository for interaction datasets. Nucleic Acids Res 2006, , 34 Database: D535-539.

7. Kerrien S, Alam-Faruque Y, Aranda B, Bancarz I, Bridge A, Derow C, Dimmer E, Feuermann M, Friedrichsen A, Huntley R, et al: IntAct-open source resource for molecular interaction data. Nucleic Acids Res 2007, , 35 Database: D561-565.

8. Pagel P, Kovac S, Oesterheld M, Brauner B, Dunger-Kaltenbach I, Frishman G, Montrone C, Mark P, Stumpflen V, Mewes HW, et al: The MIPS mammalian protein-protein interaction database. Bioinformatics (Oxford, England) 2005, 21(6):832-834.

9. Draghici $S$, Sellamuthu S, Khatri P: Babel's tower revisited: a universal resource for cross-referencing across annotation databases. Bioinformatics (Oxford, England) 2006, 22(23):2934-2939.

10. Bruford EA, Lush MJ, Wright MW, Sneddon TP, Povey S, Birney E: The HGNC Database in 2008: a resource for the human genome. Nucleic Acids Res 2008, , 36 Database: D445-448.

11. Hermjakob H, Montecchi-Palazzi L, Bader G, Wojcik J, Salwinski L, Ceol A, Moore S, Orchard S, Sarkans U, von Mering C, et al: The HUPO PSI's molecular interaction format-a community standard for the representation of protein interaction data. Nat Biotechnol 2004, 22(2):177-183.

12. Kersey PJ, Duarte J, Williams A, Karavidopoulou Y, Birney E, Apweiler R: The International Protein Index: an integrated database for proteomics experiments. Proteomics 2004, 4(7):1985-1988.

13. Aragues R, Jaeggi D, Oliva B: PIANA: protein interactions and network analysis. Bioinformatics (Oxford, England) 2006, 22(8):1015-1017.

14. Kuntzer J, Backes C, Blum T, Gerasch A, Kaufmann M, Kohlbacher O, Lenhof HP: BNDB - the Biochemical Network Database. BMC bioinformatics 2007, 8:367.

15. Prieto C, De Las Rivas J: APID: Agile Protein Interaction Data Analyzer. Nucleic acids research 2006, , 34 Web Server: W298-302.

16. Chaurasia G, Iqbal $Y$, Hanig C, Herzel H, Wanker EE, Futschik ME: UniHI: an entry gate to the human protein interactome. Nucleic acids research 2007, 35 Database: D590-594.

17. Mudunuri U, Che A, Yi M, Stephens RM: bioDBnet: the biological database network. Bioinformatics (Oxford, England) 2009, 25(4):555-556. 
18. Kohler J, Baumbach J, Taubert J, Specht M, Skusa A, Ruegg A, Rawlings C, Verrier P, Philippi S: Graph-based analysis and visualization of experimental results with ONDEX. Bioinformatics (Oxford, England) 2006, 22(11):1383-1390.

19. Razick S, Magklaras G, Donaldson IM: iReflndex: a consolidated protein interaction database with provenance. BMC bioinformatics 2008, 9:405.

20. Aric AH, Daniel AS, Pieter JS: Exploring Network Structure, Dynamics, and Function using NetworkX. Proceedings of the 7th Python in Science Conference: 2008 2008, 11-15.

21. Cline MS, Smoot M, Cerami E, Kuchinsky A, Landys N, Workman C, Christmas R, Avila-Campilo I, Creech M, Gross B, et al: Integration of biological networks and gene expression data using Cytoscape. Nat Protoc 2007, 2(10):2366-2382.

22. Espadaler J, Romero-Isart O, Jackson RM, Oliva B: Prediction of proteinprotein interactions using distant conservation of sequence patterns and structure relationships. Bioinformatics (Oxford, England) 2005, 21(16):3360-3368.

23. Aguilar D, Oliva B: Topological comparison of methods for predicting transcriptional cooperativity in yeast. BMC Genomics 2008, 9:137.

24. Ideker T, Sharan R: Protein networks in disease. Genome research 2008, 18(4):644-652.

25. Aragues $R$, Sander C, Oliva B: Predicting cancer involvement of genes from heterogeneous data. BMC bioinformatics 2008, 9:172.

26. Fornes O, Aragues R, Espadaler J, Marti-Renom MA, Sali A, Oliva B: ModLink + : improving fold recognition by using protein-protein interactions. Bioinformatics (Oxford, England) 2009, 25(12):1506-1512.

27. Hofmann-Apitius M, Fluck J, Furlong L, Fornes O, Kolarik C, Hanser S, Boeker M, Schulz S, Sanz F, Klinger R, et al: Knowledge environments representing molecular entities for the virtual physiological human. Philos Transact A Math Phys Eng Sci 2008, 366(1878):3091-3110.

28. Yu H, Luscombe NM, Lu HX, Zhu X, Xia Y, Han JD, Bertin N, Chung S, Vidal M, Gerstein M: Annotation transfer between genomes: proteinprotein interologs and protein-DNA regulogs. Genome Res 2004, 14(6):1107-1118.

29. Messier C: Diabetes, Alzheimer's disease and apolipoprotein genotype. Experimental gerontology 2003, 38(9):941-946.

30. de la Monte SM: Insulin resistance and Alzheimer's disease. BMB reports 2009, 42(8):475-481.

31. The Universal Protein Resource (UniProt). Nucleic Acids Res 2007, , 35 Database: D193-197.

32. Ogata H, Goto S, Sato K, Fujibuchi W, Bono H, Kanehisa M: KEGG: Kyoto Encyclopedia of Genes and Genomes. Nucleic Acids Res 1999, 27(1):29-34

33. Ashburner M, Ball CA, Blake JA, Botstein D, Butler H, Cherry JM, Davis AP, Dolinski K, Dwight SS, Eppig JT, et al: Gene ontology: tool for the unification of biology. The Gene Ontology Consortium. Nature genetics 2000, 25(1):25-29.

34. Andreeva A, Howorth D, Brenner SE, Hubbard TJ, Chothia C, Murzin AG: SCOP database in 2004: refinements integrate structure and sequence family data. Nucleic Acids Res 2004, 32 Database: D226-229.

35. Matthews L, Gopinath G, Gillespie M, Caudy M, Croft D, de Bono B, Garapati P, Hemish J, Hermjakob H, Jassal B, et al: Reactome knowledgebase of human biological pathways and processes. Nucleic Acids Res 2009, , 37 Database: D619-622.

36. Keshava Prasad TS, Goel R, Kandasamy K, Keerthikumar S, Kumar S, Mathivanan S, Telikicherla D, Raju R, Shafreen B, Venugopal A, et al: Human Protein Reference Database-2009 update. Nucleic Acids Res 2009, , 37 Database: D767-772.

37. Chang $L$, Jones $Y$, Ellisman $M H$, Goldstein $L S$, Karin M: JNK1 is required for maintenance of neuronal microtubules and controls phosphorylation of microtubule-associated proteins. Developmental cell 2003, 4(4):521-533.

38. Fogarty MP, Downer EJ, Campbell V: A role for c-Jun N-terminal kinase 1 (JNK1), but not JNK2, in the beta-amyloid-mediated stabilization of protein p53 and induction of the apoptotic cascade in cultured cortical neurons. The Biochemical journal 2003, 371(Pt 3):789-798.

39. Kitamura $Y$, Shimohama S, Kamoshima W, Matsuoka Y, Nomura $Y$, Taniguchi T: Changes of p53 in the brains of patients with Alzheimer's disease. Biochemical and biophysical research communications 1997, 232(2):418-421.

40. Hirosumi J, Tuncman G, Chang L, Gorgun CZ, Uysal KT, Maeda K, Karin M, Hotamisligil GS: A central role for JNK in obesity and insulin resistance. Nature 2002, 420(6913):333-336.
41. Solinas G, Vilcu C, Neels JG, Bandyopadhyay GK, Luo JL, Naugler W, Grivennikov S, Wynshaw-Boris A, Scadeng M, Olefsky JM, et al: JNK1 in hematopoietically derived cells contributes to diet-induced inflammation and insulin resistance without affecting obesity. Cell metabolism 2007, 6(5):386-397.

42. Yu XX, Murray SF, Watts L, Booten SL, Tokorcheck J, Monia BP, Bhanot S: Reduction of JNK1 expression with antisense oligonucleotide improves adiposity in obese mice. American journal of physiology 2008, 295(2): E436-445.

43. Colbran RJ: Regulation and role of brain calcium/calmodulin-dependent protein kinase II. Neurochemistry international 1992, 21(4):469-497.

44. Yoshimura Y, Ichinose T, Yamauchi T: Phosphorylation of tau protein to sites found in Alzheimer's disease brain is catalyzed by $\mathrm{Ca} 2$ +/calmodulin-dependent protein kinase II as demonstrated tandem mass spectrometry. Neuroscience letters 2003, 353(3):185-188.

45. Wang JZ, Grundke-lqbal I, lqbal K: Kinases and phosphatases and tau sites involved in Alzheimer neurofibrillary degeneration. The European journal of neuroscience 2007, 25(1):59-68.

46. Yousif MH, Benter IF, Akhtar S: Inhibition of calcium/calmodulindependent protein kinase II normalizes diabetes-induced abnormal vascular reactivity in the rat perfused mesenteric vascular bed. Autonomic \& autacoid pharmacology 2003, 23(1):27-33.

47. Illario M, Monaco S, Cavallo AL, Esposito I, Formisano P, D'Andrea L, Cipolletta E, Trimarco B, Fenzi G, Rossi G, et al: Calcium-calmodulindependent kinase II (CaMKII) mediates insulin-stimulated proliferation and glucose uptake. Cellular signalling 2009, 21(5):786-792.

48. Hye A, Kerr F, Archer N, Foy C, Poppe M, Brown R, Hamilton G, Powell J, Anderton B, Lovestone S: Glycogen synthase kinase-3 is increased in white cells early in Alzheimer's disease. Neuroscience letters 2005, 373(1):1-4

49. Schaffer BA, Bertram L, Miller BL, Mullin K, Weintraub S, Johnson N, Bigio EH, Mesulam M, Wiedau-Pazos M, Jackson GR, et al: Association of GSK3B with Alzheimer disease and frontotemporal dementia. Archives of neurology 2008, 65(10):1368-1374.

50. Wagman AS, Johnson KW, Bussiere DE: Discovery and development of GSK3 inhibitors for the treatment of type 2 diabetes. Current pharmaceutical design 2004, 10(10):1105-1137.

51. Nakagawa Y, Shimano H, Yoshikawa T, Ide T, Tamura M, Furusawa M, Yamamoto T, Inoue N, Matsuzaka T, Takahashi A, et al: TFE3 transcriptionally activates hepatic IRS-2, participates in insulin signaling and ameliorates diabetes. Nature medicine 2006, 12(1):107-113.

52. Taguchi J, Fujii A, Fujino Y, Tsujioka Y, Takahashi M, Tsuboi Y, Wada I, Yamada T: Different expression of calreticulin and immunoglobulin binding protein in Alzheimer's disease brain. Acta neuropathologica 2000, 100(2):153-160.

53. Bass J, Chiu G, Argon Y, Steiner DF: Folding of insulin receptor monomers is facilitated by the molecular chaperones calnexin and calreticulin and impaired by rapid dimerization. The Journal of cell biology 1998, 141(3):637-646.

54. Burdo JR, Chen Q, Calcutt NA, Schubert D: The pathological interaction between diabetes and presymptomatic Alzheimer's disease. Neurobiology of aging 2009, 30(12):1910-1917.

55. Shannon P, Markiel A, Ozier O, Baliga NS, Wang JT, Ramage D, Amin N, Schwikowski B, Ideker T: Cytoscape: a software environment for integrated models of biomolecular interaction networks. Genome Res 2003, 13(11):2498-2504.

56. Li W, Godzik A: Cd-hit: a fast program for clustering and comparing large sets of protein or nucleotide sequences. Bioinformatics (Oxford, England) 2006, 22(13):1658-1659.

57. Altschul SF, Madden TL, Schaffer AA, Zhang J, Zhang Z, Miller W, Lipman DJ: Gapped BLAST and PSI-BLAST: a new generation of protein database search programs. Nucleic Acids Res 1997, 25(17):3389-3402.

58. Salomonis N, Hanspers K, Zambon AC, Vranizan K, Lawlor SC, Dahlquist KD, Doniger SW, Stuart J, Conklin BR, Pico AR: GenMAPP 2: new features and resources for pathway analysis. BMC bioinformatics 2007, 8:217.

59. Hu Z, Mellor J, Wu J, Yamada T, Holloway D, Delisi C: VisANT: dataintegrating visual framework for biological networks and modules. Nucleic Acids Res 2005, 33 Web Server: W352-357.

60. Breitkreutz BJ, Stark C, Tyers M: Osprey: a network visualization system. Genome Biol 2003, 4(3):R22. 
61. Akira Funahashi MM, Hiroaki Kitano, Naoki Tanimura: CellDesigner: a process diagram editor for gene-regulatory and biochemical networks. BIOSILICO 2003, 1(5):159-162.

62. Nikitin A, Egorov S, Daraselia N, Mazo I: Pathway studio-the analysis and navigation of molecular networks. Bioinformatics (Oxford, England) 2003, 19(16):2155-2157.

63. Iragne F, Nikolski M, Mathieu B, Auber D, Sherman D: ProViz: protein interaction visualization and exploration. Bioinformatics (Oxford, England) 2005, 21(2):272-274

64. Goldovsky L, Cases I, Enright AJ, Ouzounis CA: BioLayout(Java): versatile network visualisation of structural and functional relationships. Appl Bioinformatics 2005, 4(1):71-74.

65. Demir E, Babur O, Dogrusoz U, Gursoy A, Nisanci G, Cetin-Atalay R, Ozturk M: PATIKA: an integrated visual environment for collaborative construction and analysis of cellular pathways. Bioinformatics (Oxford, England) 2002, 18(7):996-1003.

66. Hernandez-Toro J, Prieto C, De las Rivas J: APID2NET: unified interactome graphic analyzer. Bioinformatics (Oxford, England) 2007, 23(18):2495-2497.

67. Chaurasia G, lqbal Y, Hanig C, Herzel H, Wanker EE, Futschik ME: UniHI: an entry gate to the human protein interactome. Nucleic Acids Res 2007, , 35 Database: D590-594.

68. Jayapandian M, Chapman A, Tarcea VG, Yu C, Elkiss A, lanni A, Liu B, Nandi A, Santos C, Andrews P, et al: Michigan Molecular Interactions (MiMI): putting the jigsaw puzzle together. Nucleic acids research 2007, , 35 Database: D566-571.

69. Benson DA, Karsch-Mizrachi I, Lipman DJ, Ostell J, Wheeler DL: GenBank. Nucleic acids research 2007, , 35 Database: D21-25.

70. Tatusov RL, Fedorova ND, Jackson JD, Jacobs AR, Kiryutin B, Koonin EV, Krylov DM, Mazumder R, Mekhedov SL, Nikolskaya AN, et al: The COG database: an updated version includes eukaryotes. BMC bioinformatics 2003, 4:41.

71. Sayers EW, Barrett T, Benson DA, Bryant SH, Canese K, Chetvernin V Church DM, DiCuccio M, Edgar R, Federhen S, et al: Database resources of the National Center for Biotechnology Information. Nucleic Acids Res 2009, , 37 Database: D5-15.

72. Salwinski L, Miller CS, Smith AJ, Pettit FK, Bowie JU, Eisenberg D: The Database of Interacting Proteins: 2004 update. Nucleic Acids Res 2004, 32 Database: D449-451.

73. Guldener U, Munsterkotter M, Oesterheld M, Pagel P, Ruepp A, Mewes HW, Stumpflen V: MPact: the MIPS protein interaction resource on yeast. Nucleic Acids Res 2006, , 34 Database: D436-441.

74. Jensen $\sqcup$, Kuhn M, Stark M, Chaffron S, Creevey C, Muller J, Doerks T, Julien P, Roth A, Simonovic M, et al: STRING 8-a global view on proteins and their functional interactions in 630 organisms. Nucleic Acids Res 2009, 37 Database: D412-416.

75. Huttenhower C, Haley EM, Hibbs MA, Dumeaux V, Barrett DR, Coller HA, Troyanskaya OG: Exploring the human genome with functional maps. Genome research 2009, 19(6):1093-1106.

doi:10.1186/1471-2105-11-56

Cite this article as: Garcia-Garcia et al: Biana: a software framework for compiling biological interactions and analyzing networks. $B M C$

Bioinformatics 2010 11:56.

\section{Submit your next manuscript to BioMed Central and take full advantage of:}

- Convenient online submission

- Thorough peer review

- No space constraints or color figure charges

- Immediate publication on acceptance

- Inclusion in PubMed, CAS, Scopus and Google Scholar

- Research which is freely available for redistribution

Submit your manuscript at www.biomedcentral.com/submit 